\title{
The interfaces of poly(p-phenylene vinylene) and fullerene derivatives with Al, LiF, and Al/LiF studied by secondary ion mass spectroscopy and $\mathrm{x}$-ray photoelectron spectroscopy: Formation of AlF3 disproved
}

\section{Citation for published version (APA):}

Gennip, van, W. J. H., Duren, van, J. K. J., Thuene, P. C., Janssen, R. A. J., \& Niemantsverdriet, J. W. (2002). The interfaces of poly (p-phenylene vinylene) and fullerene derivatives with Al, LiF, and Al/LiF studied by secondary ion mass spectroscopy and x-ray photoelectron spectroscopy: Formation of AlF3 disproved. Journal of Chemical Physics, 117(10), 5031-5035. https://doi.org/10.1063/1.1498473

DOI:

$10.1063 / 1.1498473$

Document status and date:

Published: 01/01/2002

\section{Document Version:}

Publisher's PDF, also known as Version of Record (includes final page, issue and volume numbers)

\section{Please check the document version of this publication:}

- A submitted manuscript is the version of the article upon submission and before peer-review. There can be important differences between the submitted version and the official published version of record. People interested in the research are advised to contact the author for the final version of the publication, or visit the $\mathrm{DOI}$ to the publisher's website.

- The final author version and the galley proof are versions of the publication after peer review.

- The final published version features the final layout of the paper including the volume, issue and page numbers.

Link to publication

\footnotetext{
General rights

- You may freely distribute the URL identifying the publication in the public portal. follow below link for the End User Agreement:

www.tue.nl/taverne

\author{
Take down policy \\ If you believe that this document breaches copyright please contact us at: \\ openaccess@tue.nl \\ providing details and we will investigate your claim.
}

Copyright and moral rights for the publications made accessible in the public portal are retained by the authors and/or other copyright owners and it is a condition of accessing publications that users recognise and abide by the legal requirements associated with these rights.

- Users may download and print one copy of any publication from the public portal for the purpose of private study or research.

- You may not further distribute the material or use it for any profit-making activity or commercial gain

If the publication is distributed under the terms of Article 25fa of the Dutch Copyright Act, indicated by the "Taverne" license above, please 


\title{
The interfaces of poly ( $p$-phenylene vinylene) and fullerene derivatives with Al, LiF, and Al/LiF studied by secondary ion mass spectroscopy and $\mathrm{x}$-ray photoelectron spectroscopy: Formation of $\mathrm{AlF}_{3}$ disproved
}

\author{
W. J. H. van Gennip \\ Dutch Polymer Institute, Eindhoven University of Technology, STW 3.48, P.O. Box 513, 5600 MB \\ Eindhoven, The Netherlands \\ J. K. J. van Duren \\ Laboratory of Macromolecular and Organic Chemistry, Eindhoven University of Technology, P.O. Box 513, \\ 5600 MB Eindhoven, The Netherlands \\ P. C. Thüne \\ Dutch Polymer Institute, Eindhoven University of Technology, STW 3.50, P.O. Box 513, 5600 MB \\ Eindhoven, The Netherlands \\ R. A. J. Janssen \\ Laboratory of Macromolecular and Organic Chemistry, Eindhoven University of Technology, P.O. Box 513, \\ 5600 MB Eindhoven, The Netherlands \\ J. W. Niemantsverdriet \\ Dutch Polymer Institute, Eindhoven University of Technology, STW 3.46, P.O. Box 513, 5600 MB \\ Eindhoven, The Netherlands
}

(Received 29 April 2002; accepted 11 June 2002)

\begin{abstract}
Two mutually exclusive mechanisms have been proposed to explain the improved electron injection by the insertion of a $\mathrm{LiF}$ layer between the metal cathode and the active organic layer of organic photoelectronic devices: the dipole and the doping mechanism. The possibility of the doping mechanism was studied by investigating the interface of poly[2-methoxy-5-( $3^{\prime}, 7^{\prime}$ dimethyl-octyloxyl)-1,4-phenylenevinylene ] (MDMO-PPV) or 1-(3-(methoxycarbonyl) propyl)-1-phenyl[6,6] $\mathrm{C}_{61}(\mathrm{PCBM})$ with $\mathrm{Al}, \mathrm{LiF}$, or $\mathrm{Al} / \mathrm{LiF}$. In this mechanism, $\mathrm{Li}$ dopes the organic layer, after liberation via the reaction $\mathrm{Al}+3 \mathrm{LiF} \rightarrow \mathrm{AlF}_{3}+3 \mathrm{Li}$. If this reaction takes place, $\mathrm{AlF}_{3}$ should be detectable at the surface. However, SIMS measurements showed that $\mathrm{AlF}_{3}$ is not present at the $\mathrm{Al} / \mathrm{LiF} / \mathrm{MDMO}-\mathrm{PPV}$ and $\mathrm{Al} / \mathrm{LiF} / \mathrm{PCBM}$ interfaces. This is evidence that the proposed reaction does not occur. Other evidence that the doping mechanism cannot be the general mechanism to explain the enhanced electron injection comes from the presence of LiF on both organic surfaces. XPS measurements indicate that there is a reaction of Al with the carboxylic oxygen of PCBM, and that a LiF layer between PCBM and Al prevents this reaction. (C) 2002 American Institute of Physics. [DOI: 10.1063/1.1498473]
\end{abstract}

\section{INTRODUCTION}

Improving the electron injection into the active layer of polymer electronic devices, such as organic light emitting diodes and polymer solar cells, is one of the critical issues in their development. One way to improve the electron injection is to insert a thin layer of LiF between for example tris-(8-hydroxyquinoline)aluminum $\left(\mathrm{Alq}_{3}\right)$ and the metal cathode. ${ }^{1}$ Such a layer is already effective at the equivalent layer thickness of $1 \AA ;_{;}^{2}$ layers of seven nanometers or more, however, become detrimental to the electron injection. ${ }^{3}$ The same beneficial effect of an inserted LiF layer was noted for several other devices, containing organic compounds such as $\quad 4-4^{\prime}$-bis(2,2-diphenylvinyl)-1,1'-biphenyl (DPVBi), ${ }^{4}$ poly [2-methoxy-5-(2'-ethylhexyloxy ) -1, 4-phenylenevinylene] (MEH-PPV) ${ }^{5}$ and molecularly mixed layers of poly [2-methoxy-5- ( 3'-7'-dimethyloctyloxy ) 1, 4-phenylenevinylene) (MDMO-PPV) and 1-[3-(methoxycarbonyl) propyl]-1-phenyl[6,6] $\mathrm{C}_{61}(\mathrm{PCBM}){ }^{6}$
Several mechanisms to explain the beneficial effect of a thin layer of $\mathrm{LiF}$ on the electron injection at the cathode have been suggested: The formation of $\mathrm{a} \mathrm{Li}^{+}$polymer ${ }^{-}$or $\mathrm{Li}^{+}$molecule ${ }^{-}$charge transfer complex after the reaction of $\mathrm{LiF}$ with $\mathrm{Al}$ to $\mathrm{AlF}_{3}$ and liberated $\mathrm{Li}^{7-11}$ tunneling injection, ${ }^{1,5}$ formation of a dipolar layer, ${ }^{4,12}$ and the protection of the organic layer from reaction with aluminum. ${ }^{4,8,9,13}$

The mechanism of electron injection enhancement by the formation of radical anions or charge transfer complexes, which could be responsible for the higher device efficiencies, was first suggested by Kido et al. ${ }^{14}$ They showed that an organic layer at the cathode interface shows electron injection improvement upon the co-evaporation of a low-workfunction metal and the organic layer, which suggests that doping takes place. However, when Le et al. used LiF instead of $\mathrm{Li}$, they found that $\mathrm{LiF}$ alone does not decompose on $\mathrm{Alq}_{3}$, although a LiF layer also enhances the electron injection. ${ }^{8}$ Hence, they suggested that $\mathrm{Li}$ is liberated in the presence of $\mathrm{Al}$ and reacts with $\mathrm{Alq}_{3}$ to form the radical anion, 


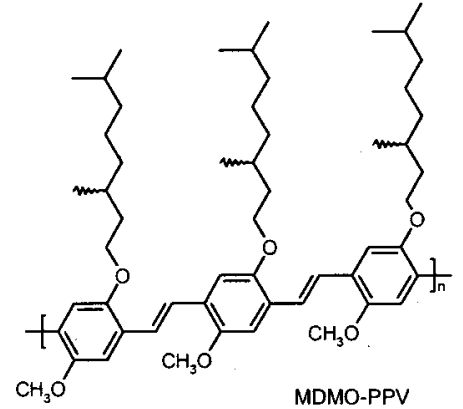

MDMO-PPV

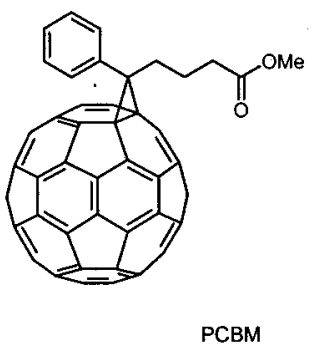

PCBM

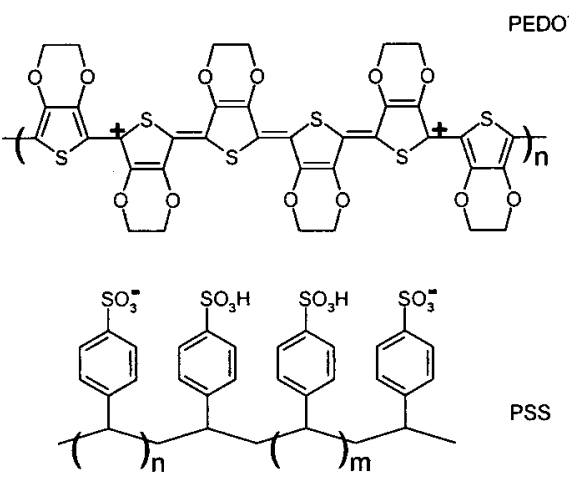

FIG. 1. Compounds used for semiconductive (MDMO-PPV:PCBM) and conductive (PEDOT:PSS) organic layers.

although they proposed no reaction scheme. Piromreun et al. claimed that $\mathrm{Al}$ reacts with $\mathrm{CsF}$ on $\mathrm{MEH}-\mathrm{PPV}$ to form $\mathrm{AlF}_{3}$ and free $\mathrm{Cs}$, which subsequently doped MEH-PPV. ${ }^{15}$ Others claimed the same mechanism for $\mathrm{LiF}$ on $\mathrm{Alq}_{3}{ }^{7,11} \mathrm{Al} / \mathrm{CsF}$ on poly(9,9-dioctylfluorene) (PFO) follows the same reaction scheme according to Greczynski et al. ${ }^{13}$ However, these authors did not observe this for $\mathrm{Al} / \mathrm{LiF}$ on $\mathrm{PFO}$, which suggests that the proposed reaction scheme is not generally applicable. Also, Yang et al. noted that significant photoluminescence quenching should be expected if alkali metal ions diffuse into the active organic layer. However, when these authors measured the photoluminescence quantum efficiency of devices with and without an inserted LiF on MEH-PPV, they found essentially the same photoluminescence quantum efficiencies for both devices. ${ }^{16}$

The tunneling injection mechanism explains the improved electron injection only in terms of the backflow current reduction, caused by the reduction of the electrode metal image force on the organic molecules by the insulating layer of LiF. This mechanism was investigated by Yang et al. when they studied devices with $\mathrm{LiF}, \mathrm{CsF}, \mathrm{CaF}_{2}$, and $\mathrm{BaF}_{2}$ layers stacked between different metal cathodes and a MEHPPV layer. They found that tunneling through an insulating metal fluoride layer cannot be the correct mechanism because of the electron injection independence of the metal fluoride layer thickness and the strong performance dependence on the capping metals on top of the metal fluorides. ${ }^{16}$ Masenelli et al., ${ }^{17}$ numerically modeling experimental data from Stößel et al., ${ }^{18}$ confirmed that the reduction of the backflow current alone cannot explain the action of $\mathrm{LiF}$, although it enhances the injection somewhat.

The aligned dipole mechanism explains the improved electron injection by the formation of a dipole in the $\mathrm{LiF}$ layer, which then lowers the work function of the metal cathode. Greczynski et al. showed that LiF deposited on a clean Al substrate shows weak dipole formation. ${ }^{19}$ Masenelli et al. demonstrated good agreement between simulations of a dipolar LiF layer and experimental data. ${ }^{17}$ Yang et al. found that devices with heavier metal fluorides exhibit less temperature dependence of the device lifetime. At an elevated temperature, thermal movement at the interface creates disorder, decreasing the orientation of the dipoles. Their interpretation was that since heavier metal fluorides show slower thermal movement, a better lifetime is expected. ${ }^{16}$ Baldo et al. remarked that an abrupt shift of approximately $1 \mathrm{eV}$ in the vacuum level is observed at all metal cathode/ $\mathrm{Alq}_{3}$ interfaces studied to date with photoelectron spectroscopy. This is evidence for charge separation near the metal, which results in dipoles at its interface with the underlying organic semiconductor. They suggested that LiF/Al cathodes improve injection by raising the Fermi energy and shifting the effective injection interface deeper into the organic film where the distribution of organic states is narrower and the hopping barrier to injection is reduced. ${ }^{12}$

Another mechanism is that $\mathrm{LiF}$ protects the active organic layer ${ }^{4,8,9,13}$ from the hot impinging metal atoms. Several authors reported on chemical damage to the $\mathrm{Alq}_{3}$ layer upon deposition of the cathode material, ${ }^{20}$ not only with $\mathrm{Al},{ }^{8}$ but also with $\mathrm{Mg},{ }^{21}$ although according to Mason et al. no bond breaking is caused by $\mathrm{Mg}, \mathrm{Na}, \mathrm{Li}$, or $\mathrm{K} .{ }^{9}$ Nevertheless, according to Baldo et al. ${ }^{12}$ chemical damage may explain the new gap states observed in ultraviolet photoelectron spectroscopy (UPS) in several studies upon deposition of the metal cathode. However, all authors seem to agree that this is a secondary reason.

Obviously the two most likely mechanisms for electron injection enhancement, dubbed the doping and dipole mechanism, are mutually exclusive, but conclusive evidence for any of these two models is hard to find, because of the complexity of the interface and because spectroscopic methods such as XPS (Ref. 22) and UPS (Ref. 23) cannot always give unequivocal information on this problem.

Knowledge about the presence or absence of the elements and compounds around the interface enables us to discriminate between the dipole and the doping model. Just as for the mixture of MDMO-PPV and PCBM, the same beneficial effect of $\mathrm{LiF} / \mathrm{Al}$ has been observed for the pure compounds. Therefore, SIMS spectra were measured at the interface of the organic and the $\mathrm{LiF}$ layers to determine the chemical state of the LiF layer on the surfaces of MDMOPPV and PCBM substrates (Fig. 1 shows the molecular formulas), taking into account the possible influence of aluminum. These spectra show that LiF does not dissociate or react with aluminum to $\mathrm{AlF}_{3}$ on both substrates, excluding the doping model for the explanation of enhanced electron injection in these substrates. Note that the validity of the 
dipole mechanism has not been proved, but that the validity of the doping model has been disproved.

Furthermore, to study possible interactions between deposited aluminum and the underlying organic layer, x-ray photoelectron spectroscopy (XPS) measurements were performed using only relative shifts which indicated a reaction between aluminum and the carboxylic oxygen of PCBM. MDMO-PPV is resistant to a reaction with aluminum.

\section{EXPERIMENT}

The materials used were poly[2-methoxy-5- $\left(3^{\prime}, 7^{\prime}-\right.$ dimethyloctyloxy)-1,4-phenylenevinylene] (MDMO-PPV) synthesized via the Gilch-route, ${ }^{24}$ 1-[3-(methoxycarbonyl)propyl]-1-phenyl[6,6] $\mathrm{C}_{61}(\mathrm{PCBM})$ generously provided by Rispens and Hummelen, ${ }^{25}$ polyethylenedioxythiophene:polystyrenesulfonate (PEDOT:PSS) from Bayer $\mathrm{AG}, \mathrm{LiF}$ from Aldrich, Al from Engelhard-Clal, and anhydrous $\mathrm{AlF}_{3}$ from Aldrich. A glass plate covered with a 160 $\mathrm{nm}$ thick layer of indium tin oxide (ITO) was used as the substrate.

All samples were transported in a dry nitrogen atmosphere to a VG Ionex system equipped with a VG Clam II analyzer, $\mathrm{Mg} / \mathrm{Al} K \alpha$ dual anode x-ray source, VG MIG-102 $\mathrm{Ga}^{+}$and VG FAB61 ion source, LEG 31F electron flood gun and M12-2s ( $<800 \mathrm{amu}$ ) quadrupole. The XPS measurements were carried out using the $\mathrm{Al}$ anode. All $\mathrm{C} 1 s$ peaks corresponding to hydrocarbon were calibrated at a binding energy of $285.0 \mathrm{eV}$ to correct for the energy shift caused by charging. The static SIMS measurements were performed with the electron impact gun (FAB 61) using Xe at $5 \mathrm{keV}$, while taking care to keep the total ion dose for each measurement within the static limit.

All samples were prepared as regular devices, except where mentioned otherwise. For this purpose the glass substrates were first cleaned by ultrasonic treatment in acetone, rubbing with soap, rinsing with demineralized water, refluxing with isopropanol, and finally UV ozone treatment. Subsequently, a layer of PEDOT:PSS was spin coated from an aqueous dispersion under ambient conditions on the cleaned substrates and the layer was dried by annealing the substrate. Then a layer of either MDMO-PPV or PCBM was spin coated from a chlorobenzene solution on top of the PEDOT: PSS layer and the sample was transferred to a $\mathrm{N}_{2}$ atmosphere glove box. Finally, for some samples LiF and/or aluminum layers were deposited by thermal evaporation under vacuum $\left(5 \times 10^{-6}\right.$ mbar, $1 \mathrm{ppm} \mathrm{O}_{2}$, and $\left.<1 \mathrm{ppm}_{2} \mathrm{O}\right)$. The following samples were prepared:

(1) Two reference samples of a $60 \mathrm{~nm}$ thick layer of $\mathrm{Al}$ or $\mathrm{LiF}$ deposited on a previously cleaned $\mathrm{Si}(100)$ wafer;

(2) one reference sample of $\mathrm{AlF}_{3}$ powder pressed into indium foil;

(3) two reference samples of pure MDMO-PPV or PCBM as the top layer of prepared-as-normal devices;

(4) four samples with a $5 \AA$ layer of $\mathrm{Al}$ or $\mathrm{LiF}$ deposited on top of either MDMO-PPV or PCBM as the top layer of prepared-as-normal devices;

(5) two samples with a $5 \AA$ layer of $\mathrm{Al}$ deposited on top of a

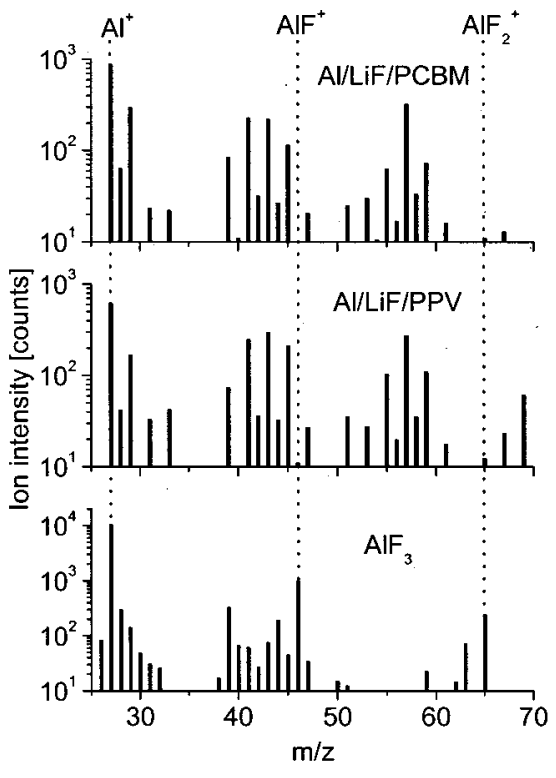

FIG. 2. $\mathrm{AlF}_{3}$ reference comparison with $\mathrm{Al} / \mathrm{LiF} / \mathrm{MDMO}-\mathrm{PPV}$ or $\mathrm{Al} / \mathrm{LiF} /$ PCBM. Note the logarithmic scale of the ion intensity axis.

$5 \AA$ layer of LiF on top of either MDMO-PPV or PCBM as the top layer of prepared-as-normal devices.

All samples were prepared in duplo, so that separate samples could be used for the SSIMS and XPS measurements.

\section{RESULTS AND DISCUSSION}

A popular explanation of the improved electron injection by $\mathrm{LiF}$ is the doping of the active polymer by $\mathrm{Li}$ liberated by a reaction between $\mathrm{LiF}$ and $\mathrm{Al}$ deposited on top of this. Although the Gibbs free energy required to liberate $\mathrm{Li}$ was estimated at $112.8 \mathrm{~kJ} / \mathrm{mol}$, making it an endothermic and hence unfavorable reaction, Mason et al. suggested that this is only the case for bulk LiF and that the reaction might be exothermic in the case of small isolated clusters of $\mathrm{LiF}^{9}$

Because the reaction would give rise to $\mathrm{AlF}_{3}$ on the surface of the organic layer, we have investigated the presence of $\mathrm{AlF}_{3}$. Figure 2 shows the comparison between the SIMS spectra of a pure $\mathrm{AlF}_{3}$ reference sample and of the $\mathrm{Al} / \mathrm{LiF} /$ MDMO-PPV and Al/LiF/PCBM interfaces. The peaks of interest of the $\mathrm{AlF}_{3}$ reference samples are $\mathrm{Al}^{+}, \mathrm{AlF}^{+}$, and $\mathrm{AlF}_{2}^{+}$at the $m / z$ values of 27,46 , and $65 \mathrm{D}$. The $\mathrm{AlF}^{+}$and $\mathrm{AlF}_{2}^{+}$peaks should be present for the $\mathrm{Al} / \mathrm{LiF} / \mathrm{MDMO}-\mathrm{PPV}$ and $\mathrm{Al} / \mathrm{LiF} / \mathrm{PCBM}$ samples, but they either have very low intensity or are completely missing. The low intensity of the $\mathrm{AlF}^{+}$and $\mathrm{AlF}_{2}^{+}$signals that are present are background signals caused by the underlying layers of MDMO-PPV and PCBM. Note that the drop in intensity for these peaks cannot be explained with the matrix effect, because then all signal intensities should drop by more or less the same amount, but the decrease in the $\mathrm{Al}$ ion signal is much less dramatic than that of the $\mathrm{AlF}^{+}$and $\mathrm{AlF}_{2}^{+}$signals.

Hence, the absence of $\mathrm{AlF}_{3}$ related signals in the SIMS spectra of the Al/LiF/MDMO-PPV and $\mathrm{Al} / \mathrm{LiF} / \mathrm{PCBM}$ samples is strong evidence that the proposed reaction between $\mathrm{LiF}$ and $\mathrm{Al}$ does not occur on MDMO-PPV or PCBM. 


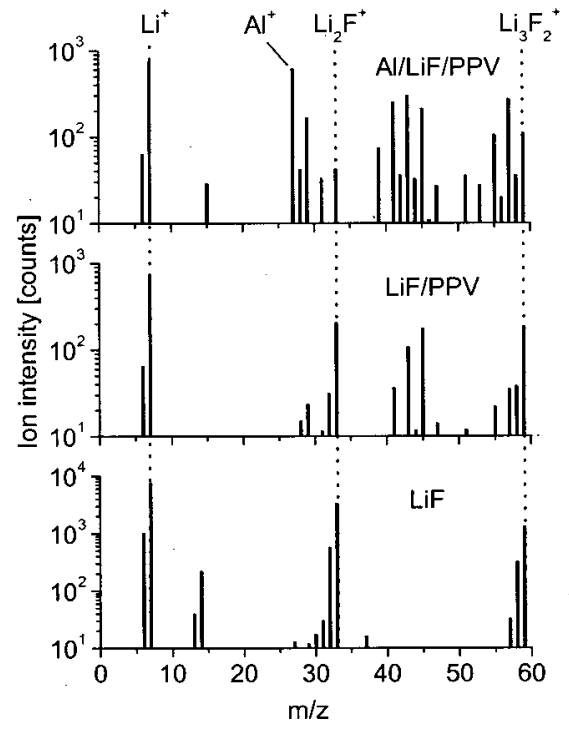

FIG. 3. Comparison of a LiF reference sample, a LiF/MDMO-PPV, and an $\mathrm{Al} / \mathrm{LiF} / \mathrm{MDMO}-\mathrm{PPV}$ sample shows that LiF stays intact on the surface of MDMO-PPV, regardless of the presence of Al.

Greczynski et al. ${ }^{13}$ claimed that $\mathrm{CsF}$ decomposes on PFO, based upon the ratio of $\mathrm{CsF}$ to the amount of $\mathrm{Al}$ needed to completely decompose $\mathrm{CsF}$, and others have made the suggestion for $\mathrm{LiF}$ on $\mathrm{Alq}_{3}$ based on rather indirect methods. However, Greczynski et al. showed with XPS that for the case of $\mathrm{LiF}$ on PFO no evidence can be found that $\mathrm{LiF}$ decomposes in the presence of Al.

Because all studied alkali and alkaline earth metal fluorides seem to improve the electron injection of the cathode, ${ }^{16}$ a general mechanism is likely to exist. Our results indicate, together with Greczynski et al.'s, that the proposed LiF/Al reaction to $\mathrm{AlF}_{3}$ is not that general mechanism.

However, the reaction to $\mathrm{AlF}_{3}$ was only proposed as a possible mechanism to obtain free $\mathrm{Li}$ atoms, which could subsequently dope the organic material. Kido et al. showed ${ }^{14}$ that a Li-doped $\mathrm{Alq}_{3}$ layer exhibited a luminance an order of magnitude higher than an $\mathrm{Alq}_{3}$ layer without $\mathrm{Li}$, suggesting that Li-doping of the organic layer may also occur for alkali and alkaline earth metal fluoride containing devices.

If $\mathrm{Li}$ is liberated on the surface of the organic material, by reaction with $\mathrm{Al}$ or in any other conceivable way, then $\mathrm{LiF}$ should no longer be visible on the surface of the organic material. Figure 3 shows a comparison between SSIMS spectra from a LiF reference sample, and of LiF on MDMO-PPV, with and without $\mathrm{Al}$ on top. The $\mathrm{LiF}$ panel at the top of Fig. 3 shows a clear ion cluster series of $\mathrm{Li}_{n} \mathrm{~F}_{n-1}^{+}$, although only a small part is shown here. The LiF/MDMO-PPV panel in the middle clearly shows the same ion pattern for LiF. Unfortunately, an $\mathrm{Al}$ layer on top of the $\mathrm{LiF}$ layer attenuates the $\mathrm{LiF}$ cluster ion signals, as shown in the Al/LiF/MDMO-PPV panel. Identical results have been obtained for the PCBM samples.

Because of the small amount of LiF deposited, the presence of $\mathrm{LiF}$ on top of the organic layers indicates that no liberation of $\mathrm{Li}$ takes place in any way, as the ion cluster series of $\mathrm{Li}_{n} \mathrm{~F}_{n-1}^{+}$can only be formed if there are large clusters of $\mathrm{LiF}$ on the surface, which is a rather unlikely occurrence if most of the $\mathrm{LiF}$ has reacted. Hence, a mechanism in which $\mathrm{Li}$ dopes the underlying organic layer is unlikely.

As mentioned before, one reaction that has been shown to occur is the reaction between $\mathrm{Al}$ and the underlying organic layer, for example with $\mathrm{Alq}_{3}$ (Refs. 8 and 9) and
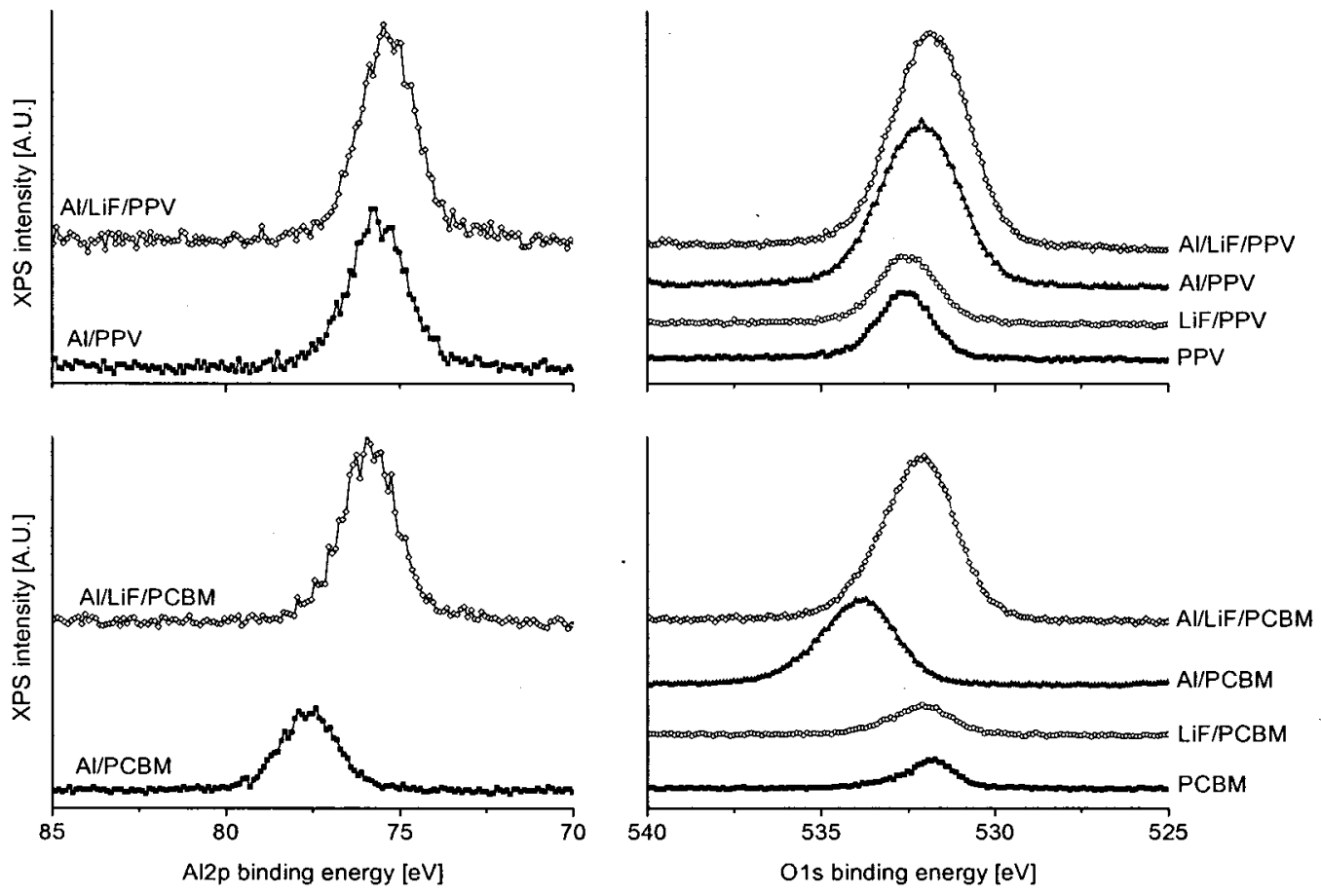

FIG. 4. Comparison of the $\mathrm{Al} 2 p$ and $\mathrm{O} 1 s$ regions of MDMO-PPV and PCBM samples suggests that PCBM reacts with Al upon adsorption if the PCBM layer is not protected by a thin layer of LiF. MDMO-PPV is insensitive to this reaction. 
PFO. ${ }^{13}$ In the case of $\mathrm{Alq}_{3}$, Le et al. ${ }^{8}$ calculated, using density-functional theory, that the first four angstrom ${ }^{9}$ of incoming aluminum will bond directly to oxygen atoms on two of the three quinolate rings in the $\mathrm{Alq}_{3}$ molecule. Greczynski et $a l .{ }^{13}$ showed that only relatively small amounts of $\mathrm{Al}$ were needed in order to cause near complete degradation of the valence band, which suggests that $\mathrm{Al}-\mathrm{C}$ complexes are formed, although the authors did not claim any specific site of reaction on PFO.

To investigate the possibility of a reaction of $\mathrm{Al}$ with MDMO-PPV and PCBM, XPS was used to systematically measure the $\mathrm{C} 1 s, \mathrm{O} 1 s$, and $\mathrm{Al} 2 p$ core-level regions of MDMO-PPV and PCBM layers with or without LiF, Al, and $\mathrm{Al} / \mathrm{LiF}$ layers on top. In the case of MDMO-PPV, shown in Fig. 4, all binding energies were within $0.1 \mathrm{eV}$ of the reference values. However, in the case of Al/PCBM a large shift of $1.5 \mathrm{eV}$ was observed for the $\mathrm{O} 1 \mathrm{~s}$ peak originating from the oxygen in PCBM compared to the same peak seen for the sample with no $\mathrm{Al}$ on top. Upon the insertion of a thin $\mathrm{LiF}$ layer, this peak shifted back $1.8 \mathrm{eV}$ to a lower binding energy. The same binding energy shift was found for the $\mathrm{Al} 2 p$ peak. No difference in the $\mathrm{C} 1 \mathrm{~s}$ region could be observed at all, indicating that carbon atoms were uneffected.

The fact that the $\mathrm{O} 1 s$ and $\mathrm{Al} 2 p$ peaks both shifted to higher binding energies by the same amount is a strong indication that the carboxylic oxygen interacts with the aluminum. The aluminum is probably not metallic but in the form of $\mathrm{Al}_{x} \mathrm{O}$, because of the extreme broadening of the $\mathrm{O} 1 s$ peak upon adsorption of aluminum and the getter behavior of aluminum in vacuum. A possible reaction could be an acid-base reaction between the carboxylic group of PCBM and $\mathrm{Al}_{x} \mathrm{O}$, with methanol and an organometallic complex between the carboxylic group and the aluminum atom as reaction products. No comparison with literature values is possible, because a related complex could not be found in the literature. $^{26,27}$

Unfortunately, verification of the proposed organometallic complex formation by SIMS is doubtful, because the most obvious peaks to look for, such as $\mathrm{AlO}^{+}$, can also originate from $\mathrm{Al}_{x} \mathrm{O}$. Another consideration is that the nature of the carboxyl group bonds with the aluminum is not known, and these bonds may be too weak to survive the impact of the primary ions. Hence, DFT calculations should be performed to verify the probability of this reaction.

\section{CONCLUSIONS AND SUMMARY}

Some relevant sandwich-type interfaces related to solar cell devices and polymer LEDs have been studied using secondary ion mass spectrometry and x-ray photoelectron spectroscopy, including Al/MDMO-PPV, LiF/MDMO-PPV, Al/ $\mathrm{LiF} / \mathrm{MDMO}-\mathrm{PPV}$, and similar interfaces containing PCBM instead of MDMO-PPV. SIMS measurements show that LiF does not react with aluminum to $\mathrm{AlF}_{3}$, nor does it react in any other way to liberate $\mathrm{Li}$ as can be concluded from the detection of $\mathrm{Li}_{n} \mathrm{~F}_{n-1}^{+}$ions. The doping of the organic layer by Li suggested by various authors is unlikely as a mechanism for the improvement of electron injection into the polymer layer.
Although MDMO-PPV seems to be stable towards the deposition of aluminum by evaporation, XPS data give evidence of a reaction between aluminum and PCBM at the carboxylic group present in PCBM, as shown by the shift of the $\mathrm{O} 1 s$ carboxylic oxygen peak upon aluminum deposition. A thin layer of $\mathrm{LiF}$ is enough to undo this shift, evidence that the $\mathrm{LiF}$ layer protects the underlying PCBM from the aluminum atoms.

\section{ACKNOWLEDGMENTS}

Financial support from the Dutch Polymer Institute (Project No. 272) and the Ecology, Economy, and Technology program (Project No. EETK97115) are gratefully acknowledged, as well as a generous gift of 1-(3-(methoxycarbonyl)propyl)-1-phenyl[6,6] $\mathrm{C}_{61} \quad$ (PCBM) from J. C. Hummelen and M. T. Rispens.

${ }^{1}$ L. S. Hung, C. W. Tang, and M. G. Mason, Appl. Phys. Lett. 70, 152 (1997).

${ }^{2}$ M. Matsumura and Y. Jinde, Appl. Phys. Lett. 73, 2872 (1998).

${ }^{3}$ T. M. Brown, I. L. Millard, D. J. Lacey, J. H. Burroughes, R. H. Friend, and F. Cacialli, Synth. Met. 124, 15 (2001).

${ }^{4}$ S. E. Shaheen, G. E. Jabbour, M. M. Morrell, Y. Kawabe, B. Kippelen, N. Peyghambarian, M.-F. Nabor, R. Schlaf, E. A. Mash, and N. R. Armstrong, J. Appl. Phys. 84, 2324 (1998).

${ }^{5}$ J. Yoon, J.-J. Kim, T.-W. Lee, and O.-O. Park, Appl. Phys. Lett. 76, 2152 (2000).

${ }^{6}$ C. J. Brabec, S. E. Shaheen, C. Winder, and N. S. Sariciftci, Appl. Phys. Lett. 80, 1288 (2002).

${ }^{7}$ H. Heil, J. Steiger, S. Karg, M. Gastel, H. Ortner, H. von Seggern, and M. Stößel, J. Appl. Phys. 89, 420 (2001).

${ }^{8}$ Q. T. Le, L. Yan, Y. Gao, M. G. Mason, D. J. Giesen, and C. W. Tang, J. Appl. Phys. 87, 375 (2000).

${ }^{9}$ M. G. Mason, C. W. Tang, L. S. Hung et al., J. Appl. Phys. 89, 2756 (2001).

${ }^{10}$ G. Parthasarathy, C. Shen, A. Kahn, and S. R. Forrest, J. Appl. Phys. 89, 4986 (2001)

${ }^{11}$ L. S. Hung and S. T. Lee, Mater. Sci. Eng., B 85, 104 (2001).

${ }^{12}$ M. A. Baldo and S. R. Forrest, Phys. Rev. B 64, 085201 (2001)

${ }^{13}$ G. Greczynski, W. R. Salaneck, and M. Fahlman, Appl. Surf. Sci. 175176, 319 (2001).

${ }^{14}$ J. Kido and T. Matsumoto, Appl. Phys. Lett. 73, 2866 (1998).

${ }^{15}$ P. Piromreun, H. Oh, Y. Shen, G. G. Malliaras, J. Campbell Scott, and P. J. Brock, Appl. Phys. Lett. 77, 2403 (2000).

${ }^{16}$ X. Yang, Y. Mo, W. Yang, G. Yu, and Y. Cao, Appl. Phys. Lett. 79, 563 (2001).

${ }^{17}$ B. Masenelli, E. Tutis, M. N. Bussac, and L. Zuppiroli, Synth. Met. 122, 141 (2001).

${ }^{18}$ M. Stößel, J. Staudigel, F. Steuber, J. Blässing, J. Simmerer, and A. Winnacker, Appl. Phys. Lett. 76, 115 (2000).

${ }^{19}$ G. Greczynski, M. Fahlman, and W. R. Salaneck, Appl. Surf. Sci. 166, 380 (2000).

${ }^{20}$ A. Rajagopal and A. Kahn, J. Appl. Phys. 84, 355 (1998).

${ }^{21}$ C. Shen, A. Kahn, and J. Schwartz, J. Am. Chem. Soc. 122, 5391 (2000).

${ }^{22}$ G. Greczynski, M. Fahlman, and W. R. Salaneck, J. Chem. Phys. 114, 8628 (2001)

${ }^{23}$ W. R. Salaneck, M. Lögdlund, M. Fahlman, G. Greczynski, and Th. Kugler, Mater. Sci. Eng., R. 34, 121 (2001).

${ }^{24}$ H. Becker, H. Spreitzer, W. Kreuder, E. Kluge, H. Schenk, I. Parker, and Y. Cao, Adv. Mater. 12, 42 (2000).

${ }^{25}$ J. C. Hummelen, B. W. Knight, F. LePeq, F. Wudl, J. Yao, and C. L. Wilkins, J. Org. Chem. 60, 532 (1995).

${ }^{26}$ SciFinder Scholar 2000 (ACS, 2000).

${ }^{27}$ C. D. Wagner et al., NIST X-Ray Photoelectron Spectroscopy Database, NIST (Version 3.2), 12-21-2001. 